\title{
ESTRATEGIAS ARGUMENTATIVAS DEL TEXTO PUBLICITARIO: LOS MECANISMOS DE ATENUACIÓN
}

\author{
JAVIER VELLÓN
}

Universitat Jaume I

\section{Resumen}

El artículo estudia los textos publicitarios desde la teoría de la argumentación, concretamente a partir de las estrategias discursivas centradas en la atenuación. Dichas estrategias se distribuyen en tres grandes grupos: las centradas en el componente pragmático, con la figura de emisor y el receptor; la dimensión semántico-pragmática, con el análisis de las modalidades oracionales; la sintáctico-semántica, con el estudio de estructuras interordinadas de carácter causal y condicional. La finalidad de tales mecanismos textuales es transmitir un mensaje en el que la agresividad propia de todo discurso performativo, como la publicidad, quede asumida en un esquema comunicativo más complejo.

Palabras clave: texto publicitario; atenuación; análisis del discurso; cortesía.

\begin{abstract}
The article studies advertising texts from the theory of the argumentation, concretely from the attenuation centred speech strategies. These strategies are distributed in three large groups: those centred in the pragmatic component, with the figure of the emitter and the receiver; the semantic-pragmatic dimension, with the analysis of the sentential modalities; the syntacticsemantics, with the study of subordinate structures of causal and conditional character. The purpose of such textual mechanism is to transmit a message in wich the own aggressiveness of any performing speech, like publicity, stays assumed in a more complex communicative scheme.
\end{abstract}

Key words: advertising text, attenuation, analysis of the speech, courtesy. 


\section{[1. Texto publicitario y atenuación}

T a singularidad de los textos publicitarios ha sido resaltada por Walvador Gutiérrez Ordóñez al considerar que no vienen caracterizados «ni por el idioma ni por el medio, sino por su orientación y finalidad perlocutiva»1. Desde tal perspectiva genérica, responden a las cualidades que Norman Fairclough atribuye a la «three-dimensional conceptions of discourse» 2 , en el sentido con que Concepción Otaola describe los discursos cuya finalidad es «incitar a hacer» ${ }^{3}$.

El fundamento perlocutivo de la práctica publicitaria, en cuanto a textos sujetos a la interacción comunicativa -según la terminología de D. Schiffrin ${ }^{4}$, se sustenta sobre una modalidad argumentativa cuyo objetivo es persuadir al destinatario, incitarlo a una actividad que lo convierta de alocutario (intérprete) en consumidor (proceso descrito por Rocío Lineros ${ }^{5}$ ) mediante la adhesión y la cooperación con la propuesta del enunciado.

De este modo, la publicidad, como acto comunicativo, ha de hacer compatible su función inductora y coercitiva, al ser una forma ritualizada de interacción, con una estrategia de colaboración necesaria por parte del receptor, que le lleve a asumir como propio un mensaje de índole impositiva.

A partir de este concepto, el texto publicitario puede interpretarse como un discurso que atenta contra los principios de la "imagen" individual y social,

\footnotetext{
1 Comentario pragmático de textos publicitarios, Madrid, Arco, 1997, p. 9.

2 Discourse and Social Change, Cambridge, Polity Press, 1992, pp. 72-43.

3 «El verbo y las expresiones directivas en el discurso político», en José Luis Girón y otros (eds.), Estudios ofrecidos al profesor José Jesús de Bustos Tovar, Madrid, Editorial Complutense, 2003, vol. II, pp. 1033-1053, cita p. 1037.

4 Approaches to Discourse, Cambridge, Blackwell, 1994, vid. pp. 397 y ss.

5 «Procesos cognitivos en el almacenamiento de la información», en José Luis Cifuentes (ed.), Estudios de lingüística cognitiva, Alicante, Universidad de Alicante, 1998, vol.I, pp. 113-127, vid. pp.114-115.
} 
noción desarrollada por la teoría pragmática, especialmente por los estudios de P. Brown y S.C. Levinson ${ }^{6}$ en torno al concepto de "face". En este ámbito, resulta sugestiva la noción de "imagen negativa" de los individuos, esto es, la que descansa sobre la conciencia de libertad personal y social, opuesta a la que se presenta como imposición, arbitrariedad, censura, en definitiva, es decir, cualquier acto que atente contra la "integridad territorial", entendida como espacio de autorrealización en la propuesta de L. R. Mao7.

Si la pretensión de la estrategia publicitaria es generar comportamientos cooperativos, conducentes a un objetivo económico explícito, el enunciado ha de presentar atenuados los contenidos argumentativos, partiendo de mecanismos discursivos que distancien el acto enunciativo, formulador de mensajes "amenazantes", de los mecanismos arbitrados por el mensaje. En otros términos, se trata de conceder prioridad a las estrategias que traduzcan la obligatoriedad en consejo, la imposición en información, el acto unidireccional en conversacional, de manera que aun transmitiendo la segunda dimensión, el proceso cognitivo implicado dé como resultado una información semántica contenida en las macroestructuras tal como establece el análisis de T. Van Dijk ${ }^{8}$.

En este artículo, por tanto, van a tratarse los mecanismos de la atenuación. Para una organización coherente de los diferentes elementos implicados en esta actividad textual, se distinguirá entre atenuantes pragmáticos (aquí se incluirá el análisis de los aspectos relacionados con los participantes en la enunciación, emisor y receptor), semántico-pragmáticos (las modalidades oracionales), y sintácticos, con las estructuras causalesconsecutivas y las condicionales.

\footnotetext{
6 Politeness. Some Universals in Laguage Use, Cambridge, University Press, 1987, vid. p. 55.

7 «Beyond politeness theory: 'face' revisited and renewed», Journal of Pragmatic, 1994, 21, pp. 451-486.

${ }^{8}$ Texto y contexto. Semántica y pragmática del discurso, Madrid, Cátedra, 1998, p. 213.
} 


\section{[2. Estrategias de atenuación}

\subsection{Atenuantes pragmáticos}

a) Relacionados con la figura del emisor

La primera constatación a este respecto es que el discurso publicitario tiende a construirse diluyendo el papel agentivo del emisor como instancia dominante del enunciado, al que se somete el destinatario como receptor de un mensaje impositivo sobre el que no tiene capacidad de respuesta.

Esta estrategia puede desarrollarse bien desde la opción de la no presencia, bien a partir de marcas que señalen hacia una posición compatible con la voluntad persuasiva en los márgenes de la interacción cortés, tal como se mencionó con anterioridad.

En lo que respecta a la ausencia de indicadores acerca del sujeto del enunciado, las formas impersonales, por una parte, o la simple modalidad mostrativo-informativa de las construcciones oracionales proyectan una imagen que pretende ocultar la huella de los protagonistas de la enunciación, «dando relevancia al universo de la referencia» en palabras de $\mathrm{H}$. Casalmiglia y A. Tusón 9 .

Más interesantes resultan, desde el punto de vista de las estrategias argumentativas, y atendiendo a la cada vez mayor complejidad de la publicidad impresa, los mecanismos generadores de marcas discursivas que apuntan a cómo el enunciador presenta los contenidos persuasivos y los vincula a una voz sobre la que gravita la responsabilidad enunciativa.

\footnotetext{
${ }^{9}$ Las cosas del decir. Manual de análisis del discurso, Barcelona, Ariel, 2004, vid. p. 137.
} 
Frente a los procedimientos anteriores, los basados en la ausencia explícita de cualquier referencia agente, los que van a ser objeto de estudio responden a un proceso de personalización de los argumentos fomentando el sentido conversacional de la interacción, de manera que el enunciado se presenta como un escenario en el que se desarrolla el microdrama en el que no sólo hay un conflicto sino, ante todo, unos personajes.

Precisamente, las estrategias en torno a la $3^{a}$ persona se vertebran a partir de esta tendencia cuyo objetivo es la concreción de las instancias enunciativas. En un primer estadio, próximo a las formas de la no persona, se localizan los textos basados en un soporte temático centrado en el producto («Micolor ha creado Fresh Magic con Neutralín...»). Se trata de una adjudicación metonímica, de base ontológica, por la que el objeto-marca asume el papel de argumento externo del verbo.

No muy alejado de este mecanismo se encuentran las diversas posibilidades de la impersonalidad semántica, sobre todo en el caso de los indefinidos existenciales que, en algunos casos, ya anuncian los indicadores personales que serán tratadas a continuación: «Donde algunos no ven ningún camino, otros ven miles» (Neumáticos BFGoodrich).

El salto cualitativo se produce cuando se contemplan los caracterizados por un sujeto-personaje, convertido en referencia argumentativa y en responsable del acto enunciativo. La fórmula dramática comienza a mostrar sus posibilidades al crear un escenario comunicativo sobre el que la ficción despliega su potencial persuasivo. El fundamento de la teoría teatral -por ejemplo, la doctrina estética del distanciamiento como fuente de conocimientoentra a formar parte del discurso publicitario.

La narración puede desarrollarse a partir de la $3^{\mathrm{a}}$ persona (un personaje real o inventado) como protagonista de un acontecimiento alusivo al tenor 
argumental (ejemplo 1, donde la figura actúa como criterio de autoridad), o, incluso, adoptando una perspectiva mucho más personalizada. En el caso del ejemplo 2, la voz de una de las protagonistas, convertida en sujeto del enunciado, propone una historia familiar relacionada con temas de gran repercusión social (la comunicación intergeneracional, la anorexia) a los que el producto da respuesta.

En esta misma dirección actúa la presencia de un yo-escénico (ejemplo 3), constituido en torno a un personaje que proyecta la dramatización de una historia, o bien la figura que mejor se ajusta al patrón del destinatario ideal (ejemplo 4), o que asume el papel de referencia como imagen sintomática del producto («Prefiero disculparme a pedir permiso»-Benicio del Toro- [Dewar's White Label]).

Esta estrategia, centrada en las posibilidades identificativas del pronombre "me", ha sido retomada en la campaña de MoviStar (ejemplo 5). En primer lugar, la iconización de la grafía ilustrativa del producto adopta, a su vez, una presencia categorial a través de su presencia en la forma pronominal, sobre la que gravita el interés perceptivo del texto. A partir de aquí, ya en la fase interpretativa, la referencia personal oscila entre el «recuérdame», que apunta hacia los protagonistas de la escena, y el «Ahora pídeme», de manera que la primera persona, responsable del enunciado, se transforma en instancia de la enunciación, y la argumentación se canaliza a través de los diferentes ejes discursivos.

Las estrategias presentadas hasta aquí en torno a la configuración de un emisor que atenúe el acto impositivo del discurso publicitario tienen en común la elaboración de un universo de ficción, donde se sitúa la referencia personal que da voz al mensaje persuasivo. Sin entrar en una controversia teórica, alejada del objetivo de estas páginas, lo cierto es que lo esbozado en torno a los 
sujetos escénicos de los enunciados apunta hacia la propia definición de los límites literarios. No hay duda de que el texto publicitario propone un «contrato fantástico« (noción aportada por D. Mainguenau y V. Salvador ${ }^{10}$ ) con el receptor, en el que se evidencia una intención de ficcionalidad. Por supuesto, tal proceso no es un fin en sí mismo sino que persigue construir las condiciones idóneas para la persuasión, recobrando el principio humanístico del «docere apud delectare», sin olvidar la doctrina brechtiana del distanciamiento de la ficción como instrumento doctrinal.

Si la primera y tercera persona han mostrado su productividad en la fijación de los ejes emisores del enunciado, el "nosotros" ha sido el que tradicionalmente mejor ha asumido dicho papel en el sistema del discurso publicitario.

El modelo más utilizado es el que convierte la impersonalidad de la marca, como referente enunciativo, en un sujeto personalizado y colectivo, de manera que la responsabilidad del producto anunciado no recae sobre un ente genérico, sino sobre un grupo homogéneo que actúa pensando en el consumidor como sucede en el anuncio del Renault Megane. En este ejemplo se aprecia, a su vez, un recurso de gran interés en este tipo de estrategia: la mención personalizadora viene acompañada de una apelación al objeto -como materia- que precede a la singularidad identificativa de la marca: «Creamos automóviles»; «Nuestro crianza» (Marqués de Cáceres); «Nuestras botas» (Timberland). El proceso significativo se desarrolla, así, entre el "nosotros" y el producto (agente/actividad) y el resultado final, que es la mención a la marca concreta, representa la actualización de la noción conceptual ya humanizada.

Es frecuente que el "yo plural" intensifique su capacidad expresiva por contraste con la individualidad del receptor: «Por ti, miles de nosotros»

${ }^{10}$ Elements de lingüística per al discurs literari, Valencia, Tàndem, 1995, p. 195. 
(Endesa). La dinámica entre la imagen colectiva y la singularidad intensifica el efecto atenuante de la marca en cuanto que se presenta una actitud conjunta cuyo fin es la defensa del individuo, así como la adecuación de la oferta a las demandas y preferencias del receptor. El carácter coercitivo, impersonal y distanciado de la empresa queda mitigado por esta insistencia en la imagen personalizada de las instancias enunciativas.

Otra de las posibilidades del "nosotros" es la implicación directa del receptor en la referencia deíctica del texto. Este recurso es propio de los mensajes institucionales, con los que la administración pretende implicar al destinatario como parte integrante de una estructura, el Estado, convertido en un ente orgánico del que forman parte los ciudadanos: «Unimos destinos» (ADIF, Ministerio de Fomento); «Lo que estamos haciendo significa un mundo» (Ministerio de Medio Ambiente, campaña de reciclaje)

En ocasiones, para lograr esta implicación el anuncio propone mensajes cuya agentividad queda en suspenso, pues es asimilable tanto al emisor como al destinatario como es el caso del anuncio de la ONCE, cuyo eslogan, «Nos queda mucho por hacer», se constituye en fórmula no sólo de índole económica sino también de esfuerzo personal por parte del colectivo de minusválidos.

El "nosotros" puede aparecer enmarcado en modalidades más humanizadas a partir de diferentes mecanismos que contribuyen a aproximar el sujeto del enunciado a la experiencia del receptor. Tal es el caso del ejemplo 6, con un diseño tipográfico en el que resaltan la letra manuscrita, el texto subrayado resultado de una supuesta acción del narrador, así como el tono dialógico del mensaje, de manera que la expresión personal de la compañía de sitúa en el nivel vivencial del destinatario

Como sucedía en el caso de la primera y de la tercera persona, también el "yo plural" puede abrirse a la dimensión ficcional, creando universos de 
representación donde la referencia personal juega con sus posibilidades deícticas, como en el caso del ejemplo 7: la primera parte del mensaje reproduce el esquema habitual de personalización colectiva de la marca-agente, para introducir un cambio posterior, determinado inicialmente por la modalidad oracional exclamativa (mecanismo de modalización que aporta la necesaria dosis de subjetividad a la argumentación), con el que adopta una perspectiva humorística que interpreta las expectativas del destinatario.

b) Relacionados con la figura del receptor.

La presentación del receptor como instancia del discurso obliga a desarrollar estrategias de atenuación que difuminen la finalidad persuasiva del macroacto comunicativo. Si en el caso del emisor era una opción argumentativa, en el del destinatario obedece a necesidades discursivas vinculadas a la selección del receptor y a su presentación como referente del mensaje.

A continuación, se presentarán algunos de los mecanismos más habituales dispuestos para contrarrestar la imagen impositiva del texto publicitario, a partir de una referencia al "tú" que lo sitúa ya no sólo como eje de la argumentación, sino que lo integra como función necesaria del contenido discursivo. El fin último es preservar la identidad del destinatario más allá del potencial coercitivo del texto publicitario.

Una primera posibilidad es la de proponer un receptor genérico, con la fórmula de finalidad: «Para aquellos que tienen instinto» (Maurice Lacroix); «Para quienes por las noches no renuncian ni a la comodidad ni al diseño» (Flex). Este distanciamiento de la señal explícita del "tú" permite abrir la virtualidad evocativa del destinatario, introduciendo un factor selectivo sobre el que debe proyectarse la interpretación del receptor. 
En este sentido, resultan interesantes los anuncios que presentan un mensaje impersonal, dirigido a un potencial destinatario sobre el que se propone una historia en torno a las sugerencias del mensaje, como aparece en el ejemplo 8.

Los enunciados vinculados con la presencia de la segunda persona tienden a difuminar los principales mecanismos de índole impositiva, esto es, la irreversibilidad del circuito comunicativo del discurso publicitario y la condición pasiva de la instancia receptora. En el primer caso, se trata de establecer un esquema basado en la dialogicidad, en la dinámica interactiva que franquea los límites entre enunciación y enunciado, para conseguir una aproximación entre la textualidad y la acción del destinatario. En lo que respecta al proceso de agentividad, el objetivo es convertir el "tú" en referencia del desarrollo argumental, cuando no directamente implicado en el resultado final del producto.

A continuación, se verán varios modelos que ejemplifican las diversas estrategias centradas en los dos parámetros comentados.

La primera variedad de atenuantes se vertebra en torno a la decisión del "tú" como criterio sobre el que convergen las diversas líneas argumentativas del mensaje. En su forma más frecuente, se presenta el producto como el resultado de una actividad -ya comentada en el apartado dedicado a la aspectualización- gestada en una trayectoria temporal y que culmina con la respuesta a las expectativas del receptor: «Ahora sabemos qué es lo más importante para ti, y lo hemos mejorado» (Electrodomésticos LG).

Otra posibilidad, en esa misma línea, es la que sitúa al "tú" como sujeto oracional, semánticamente vinculado a un verbo que implica actividad y exige un complemento argumental desarrollado, de manera que el mensaje clave reproduce, formalmente, la intencionalidad de una emisión volcada sobre la 
segunda persona: «Has decidido nuevas ideas» (Iberia). Más intensa resulta la estrategia por la que se reorienta la dirección estructural del mensaje para que la categoría del destinatario actúe como eje sobre el que se proyecta toda la actividad del resto de elementos (tópico que contextualiza el contenido del enunciado): «Tú eres tú, y ya se encargará RX300 de adaptarse a tus circunstancias» (Lexus).

Este conjunto de indicadores atenuantes encuentra su culminación en los modelos basados en la elección del destinatario como criterio argumental del texto. Son numerosos los anuncios que adoptan este formato (« ¿Mi beso o mi voz? Tú eliges» [Sharp]) que convierte al receptor en sujeto activo con capacidad de elección, lo que las estructuras informativas y sintácticosemánticas reproducen en el nivel de la microestructura. Tomemos como ejemplo el anuncio 9, sin duda sintomático de un procedimiento de gran productividad argumentativa. En él, el "tú" no sólo se presenta como clave arbitral de una decisión que cuenta con una gran diversidad de opiniones, sino que todo en el desarrollo del mensaje verbal -también en la figuración icónicase dirige hacia la frase conclusiva: «Y luego estás tú». El argumento cualitativo juega aquí un papel primordial ya que se singulariza la referencia a la segunda persona y se sitúa en el centro de una controversia colectiva. El modelo renovador de Renault se presenta así sometido al juicio público y apela al deseo de individualidad, al ansia de autoafirmación personal como criterio persuasivo: «eres tú el que nos importa, no los demás».

Si las estrategias comentadas se plantean en torno al "tú", otras optan por el formato posesivo: «Ahora, tu Citroën AX Diesel a precio de gasolina». El efecto de proximidad es evidente en cuanto que se presenta un producto vinculado al ámbito de referencias del destinatario. El anuncio 10 se construye a partir de este principio, con una formalización adversativa, que actúa como eje 
temático del escenario verbal y que permite relacionar el dominio experiencial del destinatario, en la primera parte icónicamente señalado tanto por el juego gráfico como por la disposición sintáctico-visual de los sintagmas, con la implicación entre dicha vivencia y la presencia efectiva de la Impresora HP Photosmart en su quehacer cotidiano. El macroargumento subyacente se formula a través de la conjunción entre un modelo de vida y las posibilidades del producto, y el nexo es la presencia explícita del "tú".

Las propuestas hedonistas también encuentran cabida en las dinámicas diseñadas en torno a la segunda persona. Eslóganes como «No te conformes sólo con comprar. Disfruta» (diversia.com), sitúan al "tú" en un universo marcado por el placer, la autoestima, es decir, ideas aparentemente alejadas de la actividad consumista, con su imagen socialmente desprestigiada. En el anuncio de la Generalitat de Catalunya para conmemorar el año Gaudí, el verbo "sentir" canaliza la propuesta argumental, personalmente ligada al "tú", y sirve de preámbulo a un mensaje cimentado sobre las formas deícticas, tanto de índole textual como espacial, propiciando un movimiento que va de la figuración al espacio de la enunciación y, con ello, al dominio del receptor:

En Catalunya te sentirás como en casa. Este es el salón. Así que toma asiento y relájate, porque estás contemplando la creación de uno de los arquitectos más fascinantes del mundo: Gaudí.... Tú que estás tan cerca, ¿te vas a quedar sin verlas?

La ironía es otro de los recursos atenuantes puesto que traslada el potencial amenazante del mensaje persuasivo al interés paródico del enunciado, de manera que éste actúa como foco catalizador de la atención, diluyendo así el tono impositivo del mensaje. En el ejemplo 11, la referencia personal es genérica y enmarca la modalidad imperativa de la forma verbal ("Volvamos al Mono”).

\section{2. Atenuantes semántico-pragmáticos: la modalidad oracional}


El concepto lingüístico de modalidad de la enunciación ha sido sometido a un proceso de elaboración (como recuerda T. Jiménez Juliá11) integrándolo en la teoría comunicativa, ya no como acto de habla sino con lo que José Luis Girón denomina la «orientación ilocutiva», esto es, «el tipo de papel comunicativo que elige el hablante para sí mismo y para su oyente» ${ }^{12}$. Puesto que las modalidades de la enunciación pueden reducirse a tres -la declarativa, la interrogativa y la yusiva-, expresadas a través de los «mecanismos de fuerza ilocutiva» (noción de J. M. Sadock $\left.{ }^{13}\right)$, tres son las relaciones interlocutivas entre emisor y receptor, que habrán de ser matizadas y atenuadas, en el caso del discurso publicitario:

-En las oraciones declarativas, el locutor puede situarse en una esfera de igualdad o de superioridad respecto a su interlocutor, en cuanto que posee el dominio sobre la verdad/falsedad del enunciado y deja al destinatario en la tesitura de aceptar o no el contenido informativo. -La modalidad yusiva privilegia la posición del emisor, que asume la responsabilidad de iniciar el acto comunicativo y exige del receptor una actuación de respuesta.

-En la interrogación, la preponderancia comunicativa recae sobre el receptor, que debe reaccionar a una pregunta y de cuya intervención depende el desarrollo posterior de la interacción comunicativa.

\footnotetext{
11 «Modalidad, modo verbal y modus clausal en español», en Verba, 1989, 16, pp. 175-214.

12 «Texto, gramática, historia: la codificación del acto elocutivo en las interrogativas indirectas», Clac, 2001, 8, pp. 1-17, p. 4.

13 «Las distinciones gramaticales de los actos de habla», en F. Newmeyer (comp.), Panorama de la lingüística moderna de la Universidad de Cambridge. II Teoría lingüística: extensiones e implicaciones, Madrid, Visor, 1991, pp. 229-245, vid. p. 234.
} 
En palabras de J. L. Girón ${ }^{14}$, el hablante «asume los correspondientes papeles de exhortar, declarar o preguntar» y sitúa al receptor ante la necesidad de adoptar los papeles comunicativos de «hacer, creer y decir». Desde esta perspectiva, es factible abordar el tema de la modalidad oracional en los textos publicitarios, insistiendo en su vertiente mitigadora del carácter impositivo respecto al destinatario que encierran los actos de habla descritos.

\section{a) Modalidad declarativa}

En un esclarecedor trabajo recapitulatorio, Hang Ferrer ${ }^{15}$ sintetiza los rasgos que la tradición lingüística ha adjudicado a la modalidad declarativa o enunciativa:

-Desde el punto de vista semántico, se caracterizan por su relación con la noción lógica de verdad: el enunciado será verdadero o falso en referencia a un contexto. El receptor tiene la posibilidad de actuar, creyendo o no al emisor, en una interacción en la que los interlocutores pueden situarse en un mismo nivel o bien el destinador, desde una posición dominante, legitima el criterio de verdad del enunciado, a través de un acto negociado o impuesto implícitamente.

-Desde la perspectiva pragmática, la modalidad declarativa puede contextualizarse a través de las expresiones ilocutivas más diversas, con fórmulas performativas explícitas que reflejan la actitud del emisor en la enunciación.

\footnotetext{
14 Op. cit, p. 5.

15 «Los modos oracionales en la gramática española: rasgos morfológicos, sintácticos, semánticos y pragmáticos para una taxonomía», en Linguistik on line, 1999, 4, 3, pp. 1-22.
} 
En la publicidad, la presencia de oraciones enunciativas es frecuente, especialmente en las partes de carácter expositivo-informativo: tras el impacto perceptivo de la primera fase de la recepción, la más próxima al estadio fisiológico y a las condiciones formales, visuales y externas, las fases sucesivas, las dirigidas al proceso de almacenamiento operativo de la información, se realizan sobre macroproposiciones, de índole cognitiva, y por ello, construidas en torno a una modalidad capaz de fijar la sucesión de la información semántica pertinente.

Sin embargo, no es éste el uso más interesante pues, en realidad, no singulariza al texto publicitario frente al resto de tipologías. La formalización más característica de las declarativas es la que se desarrolla en torno a su aparición como mensajes nucleares del discurso sobre el que convergen las líneas perceptivas, ocupando espacios privilegiados de la textualidad, básicamente los reservados para el eslogan.

En estos casos, se llevan a la práctica las máximas de la atenuación, ante todo por buscar el equilibrio en la posición de los interlocutores, ocultando todos los indicadores propios del acto ilocutivo, esto es, las fórmulas del tipo "presentar", "aconsejar", declarar", "proponer", en favor del enunciado como expresión de una verdad sólo sujeta al criterio de verdad y alejada de la subjetividad del destinador.

Entre todas las fórmulas, sin duda la más productiva es la constituida a partir de estructuras nominales, en una línea muy cercana al recurso habitual en los titulares de prensa: «Seguridad para la vida real» (Clase A, Mercedes Benz), «Impresionante para tus sentidos» (Simply Cinema, JBL), «El lujo de la sencillez» (Graf von Faber-Castell). En este mismo grupo se incluyen las estructuras atributivas («Las ideas revolucionarias, a veces, son suaves y silenciosas» [Míele]) y, en general, las oraciones cuyo verbo concede la 
preponderancia argumental a sus complementos («Este verano tienes una cita en Madrid» [Comunidad de Madrid]).

Joaquín Garrido ${ }^{16}$ considera que el significado de las oraciones declarativas es «su valor de verdad», por lo que resultan «más comprometidas». De ahí que las estructuras sintáctico-semánticas sean, también en el discurso publicitario, más rígidas y de formulación más explícita:

-En las construcciones oracionales, la tendencia al orden fijo de los elementos («Dockers, repelen los líquidos», «La tentación que no cesa» [Snack a Jacks]) constituye un recurso que contribuye a fomentar la imagen de un desarrollo argumental completo, configurado en torno a un núcleo.

-En el caso de la preponderancia nominal, la estructura argumental de los sustantivos neutraliza la presencia del agente, concentrando el interés en el contenido de la propia información, abriéndose hacia su derecha a través de los índices temáticos sugeridos por la dirección del argumento: «La fuerza del tiempo» (Time Force); «La evolución de la tecnología» (Alfa 56). En esta línea, son muy sugerentes las estructuras basadas en parámetros de finalidad, en las que el sustantivo sitúa el argumento y el esquema interordinado su objeto temático: «Vitalidad para seguir disfrutando» (Asturiana); «Fruta para llevar» (Granini).

Livia Gaudino-Fallegger ${ }^{17}$ analiza la presencia de estos sintagmas nominales en ámbitos como la prensa femenina, concretamente en los titulares,

\footnotetext{
${ }^{16}$ Lógica y lingüística, Madrid, Síntesis, 1993, vid. pp. $42-43$.

17 «Notas sobre la sintaxis de los titulares de las revistas femeninas», en La lengua y los medios de comunicación, Madrid, Universidad Complutense, 1999, pp. 298-310.
} 
llegando a la conclusión de que con ellos se potencia la función perceptivopersuasiva, neutralizándose otras finalidades informativas, por ejemplo las de índole situacional. No es extraño, por tanto, que las formas implicadas en esta estrategia nominalizadora tengan otros valores añadidos, vinculados con la expresividad formal, intensificada, a su vez, por el entorno icónico en el que se realizan. Así, algunos de los enunciados presentados a continuación comparten la singularidad de la proyección visual y/o auditiva: «Sensaciones intensas» (Bonka); «Culto al ego» (Vega Fina); «Una suavidad sensacional» (Café Creme Filter); «Un encanto natural» (Anna de Codorniu).

Desprovista de marcas enunciativas y de anclajes deícticos, reducida a expresiones de gran contundencia perceptiva, amplia referencialidad semántica y sustentada sobre unidades léxicas con una estructura argumental de gran eficacia, la modalidad declarativa se presenta con toda su carga de verdad objetiva, determinando una estrategia discursiva que prioriza el equilibrio entre los interlocutores.

b) Modalidad interrogativa

El uso de las modalidades marcadas en la publicidad -interrogativas e imperativas-, se relaciona con cuestiones discursivas y con la dimensión comunicativa del texto impreso:

-En primer lugar, la situación y modalidad comunicativa se caracteriza por la distancia física entre productor y receptor, lo que condiciona el sentido unidireccional del mensaje y la conciencia, por parte del destinatario, de dichos imperativos en la interacción. 
-Existe, pues, una asimetría de poder sobre el discurso, puesto que la instancia generadora es la que controla los resortes de la argumentación y la receptora sólo puede actuar aceptando las propuestas a través de su papel como consumidor.

-El mensaje parte de un colectivo y se dirige a un grupo heterogéneo, sin embargo, la comunicación publicitaria potencia el efecto individualizador de la comunicación, a partir de diferentes recursos, entre los que destaca la tonalidad dialógica.

-Finalmente, la distancia entre los interlocutores es también espaciotemporal, en cuanto que no existen, teóricamente, elementos encargados de señalar a los participantes de la enunciación sino sólo a los marcos virtuales de la comunicación.

El resultado de estas condiciones discursivas es un modelo de carácter impositivo, cuyas manifestaciones macro y microestructurales deberían ofrecer una imagen de organización muy formalizada, con esquemas de actuación controlados, expresión impersonalizada, a partir de la variedad estándar, con una argumentación sometida a las leyes de la causalidad, con conectores explícitos que cohesionen la manera cerrada del proceso discursivo.

Frente a ello, la modalidad interrogativa -y también la imperativa, como veremos a continuación-, propone una orientación atenuada del mensaje publicitario, fomentando diversas estrategias cuyo denominador común es el sentido aproximativo respecto a las expectativas del destinatario:

-En primer lugar, actúa con la finalidad de diluir la distancia comunicativa entre emisor y receptor, propia de los textos escritos, 
potenciando una tonalidad conversacional que convierte la aserción subyacente en una interacción negociada.

-A su vez, fomenta la complicidad afectiva entre ambas instancias, pues toda pregunta implica una parte de consenso, sobre todo en torno al conocimiento del producto o, como veremos, sobre aspectos socioculturales compartidos.

-Además, la interrogación, al favorecer el «carácter abierto de la proposición», en palabras de H. Ferrer Mora ${ }^{18}$, oscila entre la función apelativa, propia de la modalidad exhortativa, y la expresiva, propia de la declarativa. Esta indefinición semántico-pragmática la convierte en procedimiento adecuado para un discurso, el publicitario, que precisamente se mueve entre la finalidad persuasiva, con las estrategias centradas en el receptor, y la informativa.

A la hora de valorar los diferentes usos de la interrogación en la publicidad, más allá de las funciones discursivas comentadas, pueden detallarse tres grandes modelos de actuación.

El primero se construye en torno a un esquema conversacional, en el cual la pregunta se convierte en síntoma del discurso dialógico. Además de romper con la línea enunciativa, modalizando el enunciado, la presencia de dicho indicador intensifica la imagen coloquial del texto y, con ello, la aproximación afectiva al universo vivencial del receptor.

En ocasiones, la textualidad central del anuncio reproduce el desarrollo de un diálogo: «Automóviles que funcionan con hidrógeno, ¿un espejismo? No. Ya son una realidad con la tecnología innovadora de BASF»; «¿Sabes cómo te

\footnotetext{
18 Op. cit., p. 9. 
sentirás si disfrutas de las clementinas cada día? OK»; «Un e-mail en mi móvil, ¿qué vendrá después?» (Movistar).

Pero la fórmula más interesante es la que presenta el texto formando parte de una interacción dialógica que excede el propio límite de la ficcionalidad textual, apuntando, por tanto, a la instancia de la enunciación y, con ello, al dominio del destinatario: «...y tú, ¿qué esperas de tu pareja? Que me estimule y que sea excitante. Lo mismo que espero de un preservativo» (Durex). La disposición del mensaje verbal lo sitúa en un contexto conversacional y su inicio se vincula con la apertura del turno de habla.

No siempre es tan explícito el anclaje con la situación comunicativa. Numerosos anuncios se inician con una pregunta cuyo objetivo es, precisamente, abrir las posibilidades de aparición de una réplica que contiene la clave argumentativa del enunciado: «¿Whisky? Lo nuestro es Magno con hielo»; «¿Pasar de sensaciones? Ponte al día» (Winston); «¿Ultra volumen para tus pestañas? ¡Ultra rápido!» (Volum Express Maybelline); «¿La vuelta al mundo? Mejor en compañía» (LM). Más interesantes resultan los ejemplos en los que la apelación al "tú" está presente: «¿Cómo irte de compras por Europa con 18000 euros en el bolsillo? Simplemente lo sabes» (Tía Lusso, licor de crema); «¿Te va la marcha? Razón de más para que no la pierdas» (Columbia, deportivas).

El segundo modelo interrogativo tiene como rasgo distintivo el hecho de que la argumentación parte de una invocación directa al "tú" del destinatario, de manera que la pregunta adopta una tonalidad exhortativa que, por una parte, cumple la función pragmática de incidir en la atención del destinatario, proponiendo así un acto perlocucionario, y, por otra, actúa como estrategia capaz de generar diversos itinerarios argumentativos.

En este grupo cabe distinguir, primeramente, los que suponen una apelación directa a la situación del receptor, construidos según el modelo la 
interrogativa total, proponiendo una interacción más comprometida que sólo espera una respuesta con un sentido dirigido hacia el referente: «¿Y tú? ¿Te sientes cómodo con tu coche?»(Chrysler); «¿Tienes hora?» (Racer); «Tus hijos no paran quietos...¿Te los vas a perder?» (Kodak); «¿Estás preparada para disfrutar de los ultrasonidos?» (Hydrosonic); « ¿Te gustan las braguitas Tanga?»; «¿Te gusta lo dulce?» (Natreen).

Algunas de estas preguntas proponen un ámbito significativo que no se agota en la simple afirmación del destinatario, pues la contestación supone la aceptación de un universo conceptual creado por el enunciado: «¿Quieres ser princesa por una noche?»(Agua fresca de rosas, Adolfo Domínguez); «¿Has estado en algún lugar interesante últimamente?»(Land Rover). El ejemplo 12 presenta una combinación de ambas fórmulas. Elaborado a partir de la modalidad interrogativa, las preguntas van creando un mundo posible donde cobra sentido el término nuclear del mensaje: «¿Eres una yoganista?»

Otras fórmulas interrogativas plantean cuestiones de mayor transcendencia para el destinatario, aportando el argumento central del anuncio: «¿De qué te sirve ir seguro, si lo que más quieres está en el de al lado?» (Daewoo Nubira); «¿Cuánto hace que no descubres algo nuevo cada día?"» (Repsol).

Para cerrar esta segunda estrategia basada en la interrogación, resulta sugerente la publicidad de la marca de tabaco Winston que, ante la opción de un nuevo símbolo, pregunta: «¿Qué símbolo habrías elegido tú?», implicando al receptor en una decisión de la que depende la propia imagen del producto. Las connotaciones metapublicitarias son evidentes y, a su vez, aparecen enmarcadas en una tonalidad modal que oscila entre la pregunta, la petición y la llamada a la actuación. Una propuesta performativa, en suma, que convierte la apelación al "tú" en un mecanismo privilegiado de la argumentación. 
La tercera modalidad interrogativa en el discurso publicitario presenta una imagen más impersonal, en cuanto que se eliminan los indicadores que señalan al destinatario como referente de la pregunta, integrándolo en el proceso argumentativo. Puesto que se adopta una perspectiva genérica, el tono conversacional se abre a nuevas posibilidades, entre las que cabe destacar las siguientes:

-Preguntas que apuntan a un receptor implícito, ya que se eliminan de la superficie textual los formatos deícticos («sufres, tienes...»), precisamente para potenciar el valor cuantitativo de los contenidos expresados: «¿Acidez? ¿Ardor de estomago? ¿Indigestión? Rennie, antiácido rápido y eficaz»; «¿Problemas de estreñimiento?» (Verolax). -Falsas interrogaciones que contienen una afirmación. La modalidad sólo propone, en este caso, un marco diferente para la enunciación declarativa en la línea de las estrategias atenuantes: «¿Sabía usted que Freixenet es el cava que más se consume en el mundo?».

-Cuestiones que se aproximan a la variante retórica, en cuanto que la pregunta sólo admite una línea interpretativa guiada por el resto del texto icónico-verbal: «¿Hay algo más cómodo que la cámara digital Kodak DC3800?»; «¿Quién sabe más de la noche?» (Licor 43).

-Finalmente, la propuesta genérica permite todo tipo de juegos conceptuales, que van desde la ironía a la puesta en cuestión de los tópicos propagados desde el propio discurso publicitario, apelando así a colectivos amplios y heterogéneos que se sienten identificados con la apelación: «¿A quién no le gusta el picnic?» (Avensis Picnic); «¿Quién dijo que las mujeres nunca tenemos qué ponernos?» (Pielsa); «¿Es genéticamente posible para el hombre ir en el asiento del 
copiloto sin murmurar ni dar instrucciones compulsivas?» (Wagon Rt, Suzuki).

c) Modalidad imperativa

El empleo de la modalidad imperativa supone siempre crear una situación comunicativa en la que el locutor accede a una posición de superioridad con respecto al receptor, puesto que asume un papel activo en la acción verbal y exige de su interlocutor una reacción ajustada a los condicionantes expuestos en el enunciado.

El discurso publicitario, respondiendo a su carácter persuasivo, supone un acto impositivo que, de manera más o menos explícita, se esboza a partir de la modalidad yusiva. La presencia de indicadores imperativos es una constante en los textos, si bien su ubicación no tiene por qué ser la del eslogan. En cualquier caso, la publicidad, sin renunciar a estos postulados lindantes con la exhortación, propone diversas estrategias atenuadoras de la fuerza ilocutiva contenida en estos enunciados.

De esta manera, aunque es cierto que con este tipo de oraciones el hablante «actúa sobre el oyente», como indica José M. González ${ }^{19}$, para conseguir un fin que pasa por la actividad de éste, no lo es menos que su presencia contribuye a impulsar la tonalidad conversacional comentada anteriormente y activa todo un universo de posibilidades interaccionales entre las instancias de la enunciación. Todo ello, a partir de una serie de modelos atenuadores, difíciles de sistematizar por su talante creativo, pero que responden a las siguientes tendencias:

\footnotetext{
${ }^{19}$ La oración simple, Madrid, Arco, 1993, p. 61. 
-Una de las más interesantes es la que atenúa el efecto de la imposición desplazando la modalidad imperativa a aspectos vinculados con el producto, evitando cualquier mención a la obligatoriedad de consumirlo. En ocasiones, el tema de la exhortación se relaciona con el resultado de la aplicación del referente («iEnseña el ombligo!» [Sveltesse]; «Refréscate» [Bacardi Breezer]), en otras a un acto vinculado sólo tangencialmente con el objeto («Regálale 1’3 segundos de trash metal punk» [Renault Clio]) o a un aspecto particular de su caracterización («Acostúmbrate a verlo de lejos» [Ford Duraturq]). En el caso de que la exhortación verbal pueda contener un principio impositivo muy directo, la imagen atenúa lo expuesto abriendo el enunciado a otras posibilidades significativas (ejemplo 13). En algunos casos, la orden se aleja completamente del entorno referencial del producto, como en el caso del ejemplo 14, con un eslogan enérgico dirigido a una campaña promocional de la marca en los medios de comunicación.

-Otra estrategia en torno a la modalidad yusiva se basa en proponer al receptor un acto determinado por un signo positivo, de manera que se implica al consumidor en una orden caracterizada por su buena imagen social. Así, en «Expulsa tu agresividad antes de conducirlo» (Renault Clio Sport), se atenúa el tópico que singulariza este tipo de modelos de automóvil por su competitividad, su velocidad, siempre en un entorno juvenil, y se logra invocando una forma imperativa dirigida, precisamente, a mitigar ese estereotipo. En esta misma línea se sitúa el uso de verbos que apuntan hacia aspectos positivos de las conductas humanas y sociales. Tal es el caso del verbo "compartir" en «Comparte tu mirada» (Nokia). 
-El distanciamiento absoluto de exhortaciones relacionadas directamente con el producto es otro de los mecanismos arbitrados por la publicidad como recurso atenuante. En este sentido, la aportación de la ironía contribuye a convertir la imposición formal en un argumento desprovisto de todo carácter negativo. Tal es el caso del anuncio 15, con el uso de la expresión de la jerga juvenil cuyo sentido se subraya, en su comicidad literal, por la imagen, permitiendo alejar la atención del receptor de lo que es una indicación sobre la presencia del whisky Ballantine's.

-Frente a los modelos comentados anteriormente, otros anuncios, de vocación eminentemente juvenil, proponen una orientación diferente en el marco de la exhortación. Se trata de textos en los que se apela a valores propios de la edad, insistiendo en actitudes provocativas, de osadía, atrevimiento, incitando al cambio, la rebeldía, la ruptura con tópicos y falsas creencias. En el caso de un maquillaje colorista e innovador, se utiliza la siguiente fórmula: «Atrévete. Demuestra quién eres y despierta tu belleza con la fuerza de los colores de la Avanzada Tecnología de la Luminosidad» (Shiseido). La aparición de verbos de acción, que implican una voluntad del sujeto agente, caracteriza a esta tipología de anuncios, muchos de los cuales se centran en productos de higiene íntima femenina. Tal es el caso del ejemplo 16, en el que la invocación al receptor («Atrévete. No te arrepentirás») establece una relación entre dos referentes, de manera que se atenúa no sólo la orden, sino la actividad planteada, en un proceso eufemístico muy habitual en este tipo de productos. 


\section{3. Atenuantes sintáctico-semánticos}

El estudio de las «expresiones compuestas equilibradas» (A. López ${ }^{20}$ García) abre un sugestivo campo de análisis aplicado al discurso, ante todo si se pone el énfasis en su condición de estructuras informativas que formalizan un enunciado basado en la sucesión tema/rema y en la interacción emisor/receptor.

Las aportaciones de la lingüística en torno a las denominadas tradicionalmente oraciones interordinadas permiten un cambio de perspectiva respecto a los excesos de la descripción formalista, favoreciendo una nueva orientación que se ajusta perfectamente a las necesidades interpretativas del discurso argumentativo. Su inclusión en la categoría de los atenuantes permite destacar tres aspectos ilustrativos de dichas fórmulas expresivas (con especial atención a las condicionales, causales-consecutivas y las de finalidad):

-En primer lugar, la estructura binaria, que establece una relación de interdependencia entre los miembros de la construcción. Es ésta una condición básica, ya que determina un modelo de interacción que se ajusta tanto a la propuesta de un desarrollo argumentativopersuasivo como a la relación entre las instancias del emisor y del receptor.

-Como indica V. Salvador ${ }^{21}$, sobre tal tipo de construcción binaria existe una proyección semántico-pragmática en término de causa y efecto, de manera que «fa més comprensibles les categories 'indici per al coneixement' i 'constatació personal' com una mena de factors

\footnotetext{
${ }^{20}$ Op. cit., pp. 91 y ss.

21 "Les construccions condicionals i les concessives", en Joan Solà y otros (eds.), Gramàtica del català contemporani, Barcelona, Empuréis, 2002, vol. III, pp. 2979-3027, vid. pp. 2980 y 2987.
} 
causals des d'una perspectiva psicològica de subjectivitat egocèntrica». Este sentido prototípico subyace a una gran parte de los esquemas aquí estudiados y explica su operatividad en la estrategia discursiva del texto publicitario.

-Finalmente, estas expresiones reproducen una estructura de base perceptivo-comunicativa, centrada en el desarrollo de la tematicidad y en su progreso hacia la información remática. Este modelo se reproduce en la formalización del mensaje, en aspectos como el orden y queda fijado, además, en la gramaticalización de los conectores, convertidos en mecanismos pragmáticos activadores de implicaturas en la competencia del hablante. Los vínculos entre lo que se propone como información compartida y asumida, la aportación remática, entre lo que se convierte en marco de la argumentación (como apelación a los "mundos posibles") y la concreción persuasiva, pasa a ser una estrategia con múltiples posibilidades evocativas en el discurso publicitario.

Entre todas las expresiones compuestas referidas, sin duda en el terreno publicitario destacan las condicionales.

La fórmula condicional más frecuente es la que cumple los siguientes requisitos:

-En primer lugar, la prótasis, que propone el condicionante como «hipótesis sobreentendida ubicada en mundos posibles conceptuales»(A. López ${ }^{22}$ ), se sitúa como referencia del estado del receptor, bien proponiendo un acto, un estado, una situación o deseo

22 Op. cit., p. 130. 
del "tú", cuyo desarrollo argumental se proyecta hacia la apódosis, como indicador remático que propone una consecuencia lógica que es el producto. De este modo, la estructura binaria, la incidencia de los interlocutores y la progresión informativa se vinculan a través de la expresión condicional como marco argumentativo del anuncio.

-En segundo lugar, la tendencia causativa, siguiendo el modelo "puesto que...entonces", coincide con la ordenación tema/rema y se vincula con formalizaciones más explícitas de la relación causal que se analizarán a continuación (“Porque...(tema), entonces...(rema)”).

-Además, es perceptible el dominio casi absoluto de la modalidad indicativa, en lo que se han denominado condicionales reales, y que desde la perspectiva cognitiva de la comunicación cabe interpretarlas en términos de accesibilidad (según expone E. Mejías-Bikandi23): el uso del modo indicativo permite relaciones de accesibilidad entre espacios mentales sucesivos, mientras que el subjuntivo tiende a bloquearlas. El modelo binario de la argumentación, así como la formulación explícita de los vínculos causales en los textos publicitarios, exigen un recorrido modal diáfano.

En la mayor parte de los anuncios analizados, la prótasis ocupa el lugar temático, proponiendo marcas argumentales de diversa índole:

-Un modelo frecuente es el que se centra en presentar una acción del destinatario, bien para demandar su continuación lógica a través del producto -es el más claramente consecutivo- («Si cuidas tu piel, ¿por

\footnotetext{
23 «Space accesibility and mood in Spanish», en Fauconnier \& Sweetser (eds.), Spaces, Worlds and Grammars, Chicago, University Press, 1996, pp. 157-178, vid. p. 175.
} 
qué no cuidas también tu colesterol?» [Flora Pro-activ]), bien para extraer conclusiones ( $\mathrm{Si}$ te pasas, te lo pierdes» [Conselleria de Bienestar Social-Generalitat Valenciana]), o para deducir consecuencias propias o en terceros ( «Si pierdes la calma, alguien puede perder mucho más» [DGA]).

-Otro ámbito de referencia es el localizado en los deseos, voluntad o preferencias del destinatario, de manera que la apódosis cumpliría con tales expectativas señalando indicialmente hacia el producto: «Si tiene un deseo en el corazón, tiene un crédito en el bolsillo» (Supercompra BBV), «Si quieres ir a la última, Freshlook. Cambia el color de tu mirada».

-Muy sugestiva resulta la posibilidad de argumentar a partir de un condicionante vertebrado a partir de las creencias, ideas o pensamientos: «Si piensas en cuarzo, piensa en resistencia» (Silestone).

-Finalmente, la condicional puede también expresar un estado del receptor que lo sitúa en el marco adecuado para convertirse en consumidor, determinando así la transición entre la simple función pasiva del destinatario y la activa, implicándole en el uso de un producto para el que se ha determinado su condición idónea: «Si con tu fuerza de voluntad no es suficiente, con Nicorette puedes acabar con el tabaco».

Lo condicional se convierte, así, en una categoría que aglutina diversas modalidades expresivas, pragmáticas y argumentativas, de manera que tal modelo está presente incluso en anuncios cuya formalización no se canaliza a través de sus indicadores constructivos habituales: «Cuando te haces una 
herida, Cristalmina. No tiene color». La apelación al "tú", la situación tematizada, se convierten en funciones indiciales de la construcción condicional y se extienden a través de diversas estructuras y esquemas argumentativos.

Esta importancia se observa, incluso, en anuncios cuyo esquema condicional tiende hacia la impersonalidad, de manera que constituye el núcleo informativo del texto, bien porque abre un proceso de implicaturas en su relación con la imagen (ejemplo 17), bien porque inicia un razonamiento genérico que gradualmente se dirige hacia la concreción del producto: «Si algo es dulce, ¿para qué añadirle azúcar?» (Minute Maid, sin azúcares añadidos).

El prototipo causativo tiene su actualización más aproximada en las denominadas expresiones causales y adyacentes (entre las que tradicionalmente se ha destacado a las finales).

Su uso más habitual responde a la tendencia informativo-expositiva de algunos textos incluidos en el anuncio, básicamente los de modalidad descriptiva, encargados de completar y dotar de contenido comunicativo la función persuasiva del eslogan.

Sin salir de esta primera finalidad, encontramos textos en los que la estructura causal más que un simple modelo sintáctico que enmarca el desarrollo argumentativo constituye el verdadero núcleo del discurso. Tal es el caso del ejemplo 18, en el que el tono conversacional, determinado por el estilo directo del texto inicial, continúa en el espacio habitualmente reservado, en la publicidad del automóvil, a la modalidad informativa, proponiendo un progreso remático que nada tiene que ver con la previsible caracterización técnica, sino que se ajusta a la coherencia irónica del comienzo. La conclusión «SEAT Arosa. El motivo es lo de menos»- plantea una síntesis del proceso gradual de inserciones causales, lo que tiene la apariencia de ser una referencia a la competencia comunicativa del destinatario. 
La incidencia del desarrollo remático, a partir de las fórmulas causales en el núcleo argumental del anuncio, produce estrategias de sumo interés que pueden llegar a organizar el itinerario receptivo del texto. En el ejemplo 19, la primera alusión -«Les hemos mandado a la cárcel»-, anclada en el referente de la imagen, obliga a continuar la lectura en dirección a las expresiones causales que, a su vez, gradúan perfectamente el interés y el proceso de desvelamiento de la información aportada respecto al enunciado primero: "Porque son solidarios"; "Porque son voluntarios de Solidaridad para el Desarrollo".

Una variante muy ilustrativa, por sus evidentes similitudes con las expresiones condicionales, es la que plantea la causa como tema del enunciado, de manera que la referencia posterior al producto aparece como consecuencia lógicamente deducible de la premisa inicial: «Porque las mejores cosas de la vida, no tienen por qué cambiar. Imperial Clásica» (El Pozo); «Porque todos los hombres tienen Allure» (Allure de Chanel).

A partir de esta distribución de la estructura binaria -un arranque temático situado en la causalidad y una aportación remática centrada en el desarrollo- se han organizado algunos anuncios, como los que formaron parte de la campaña del Ministerio de Medio Ambiente, uno de cuyos modelos es el que se muestra en el ejemplo 20. En él, la fórmula inicial situada entre la expresión causal y final, dos modalidades próximas, en cualquier caso, abre el proceso comunicativo que tiende hacia una consecuencia que se presenta como resultado de una acción institucional, en la que también se implica al destinatario mediante el argumento cuantitativo. La organización binaria, en dos planos, dos imágenes y dos cláusulas, constituye el marco argumentativo que posteriormente se somete a una glosa explicativa. La continuidad metafórica entre imágenes determina la dirección del itinerario de recepción sobre el que se superpone la estructura oracional causativa. 


\section{Conclusión]}

A lo largo del presente trabajo se han revisado algunas de las principales estrategias atenuantes del discurso publicitario, tanto en su dimensión pragmática, como semántica y formal. Tales mecanismos surgen de la necesidad de presentar un mensaje en el que la finalidad performativa ha de mitigarse en su actualización lingüística, de manera que el destinatario se sienta implicado en su contenido y no sujeto de una comunicación agresiva cuyo fin es transformar su condición de receptor en consumidor.

El texto-acción, característico de la persuasión publicitaria, desarrolla una interacción comunicativa, de claro signo impositivo y, por ello, supone una agresión contra los valores asociados a la imagen pública e individual del destinatario. Se hace necesario, por tanto, que se habiliten procedimientos mitigadores del impacto persuasivo, que favorezcan una visión atenuada del mensaje, a través de estrategias que implican al componente verbal en sus diversas manifestaciones comunicativas: desde la modalidad oracional a la presencia del sujeto, pasando por la integración del destinatario como función del proceso argumentativo. 


\section{APÉNDICE: IMÁGENES COMENTADAS}

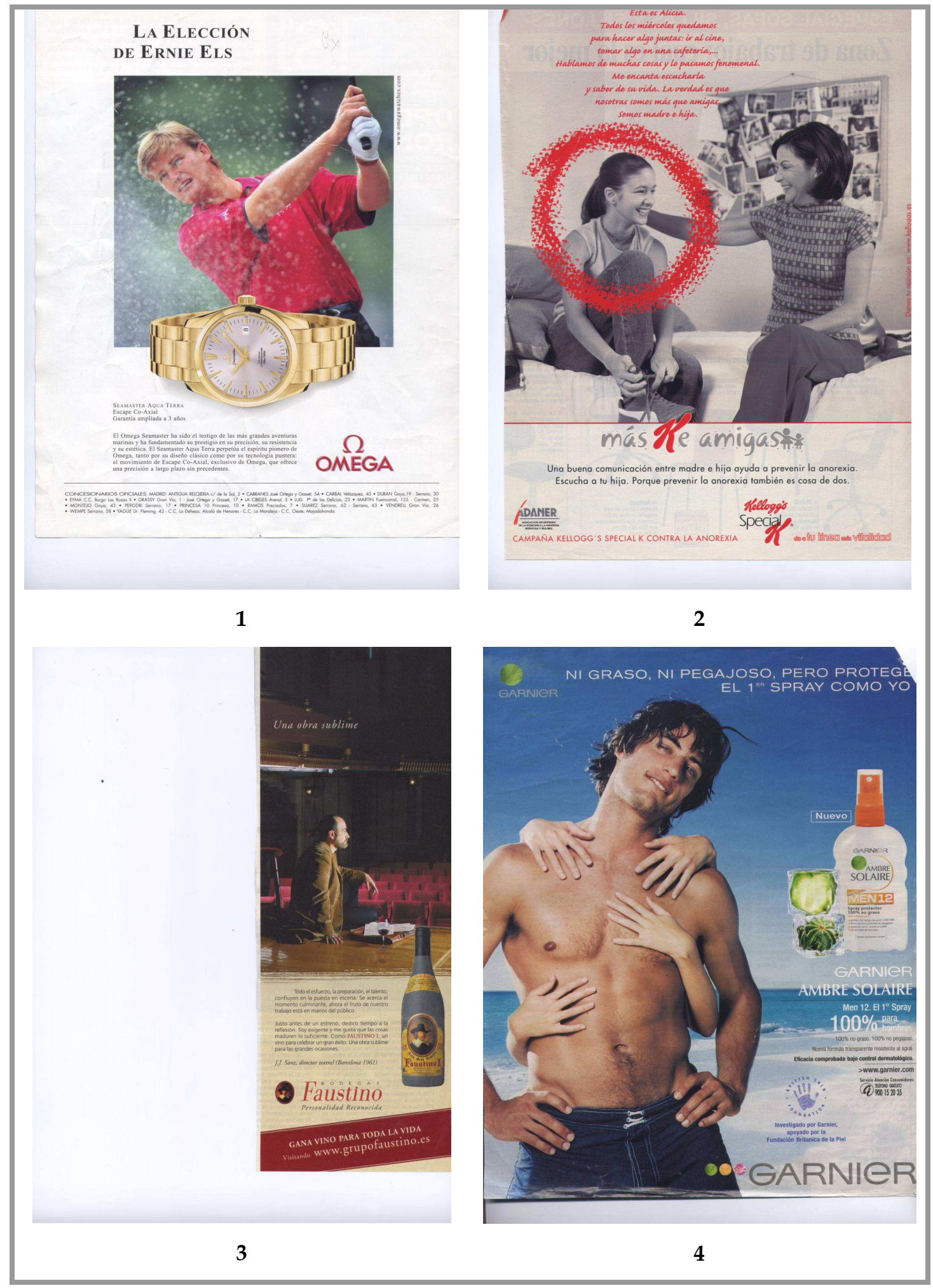




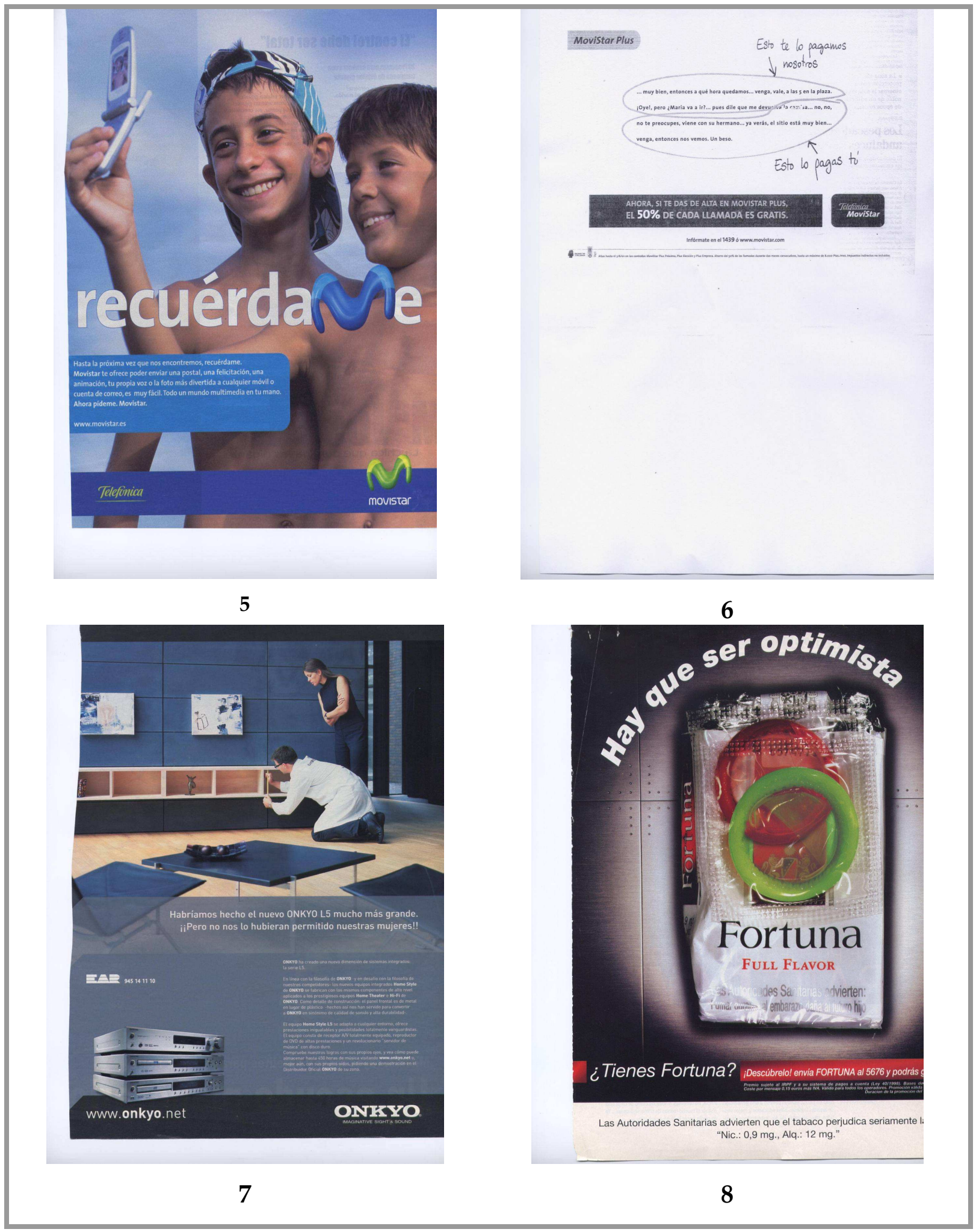




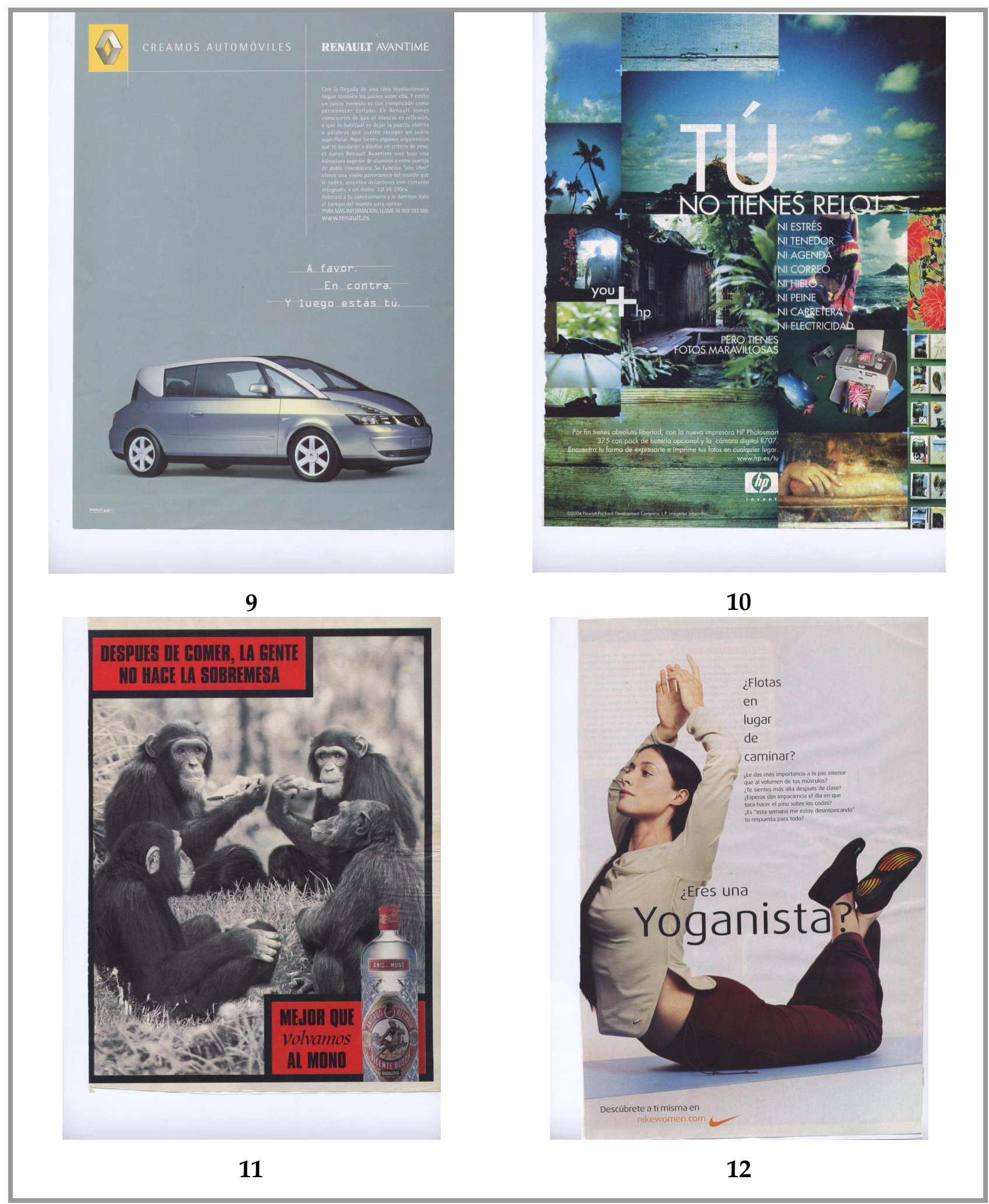




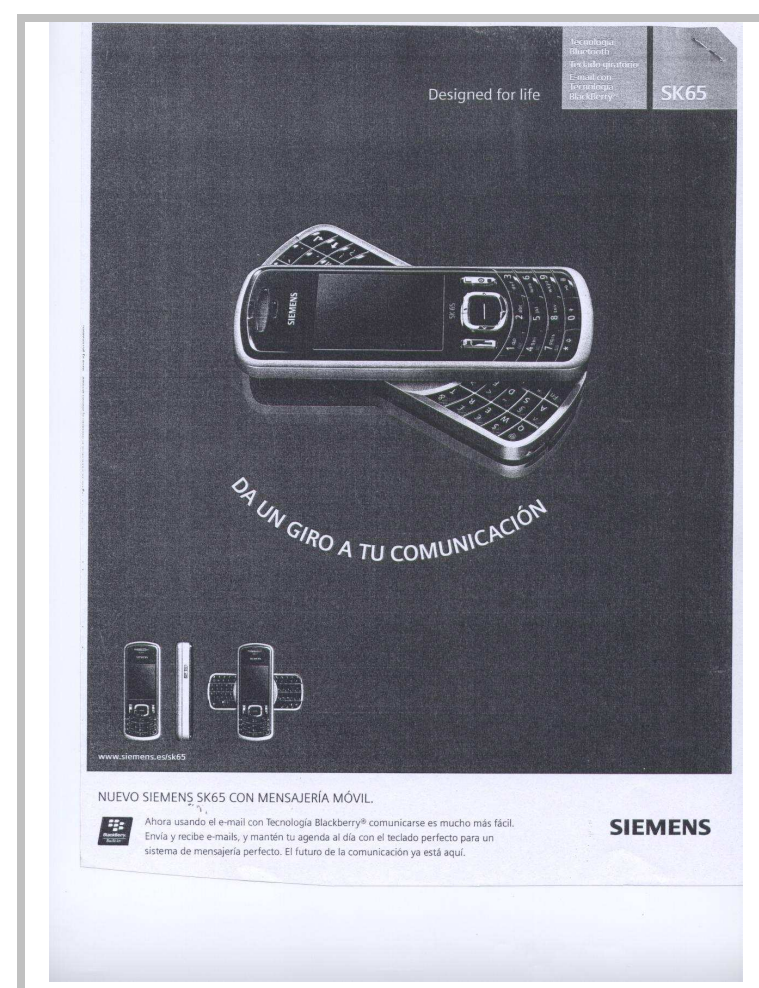

13

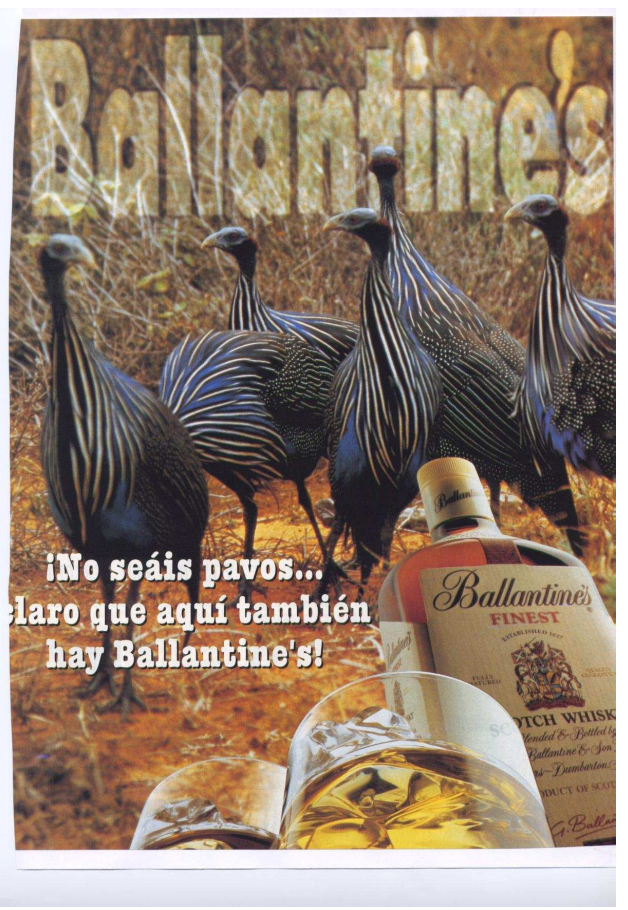

15

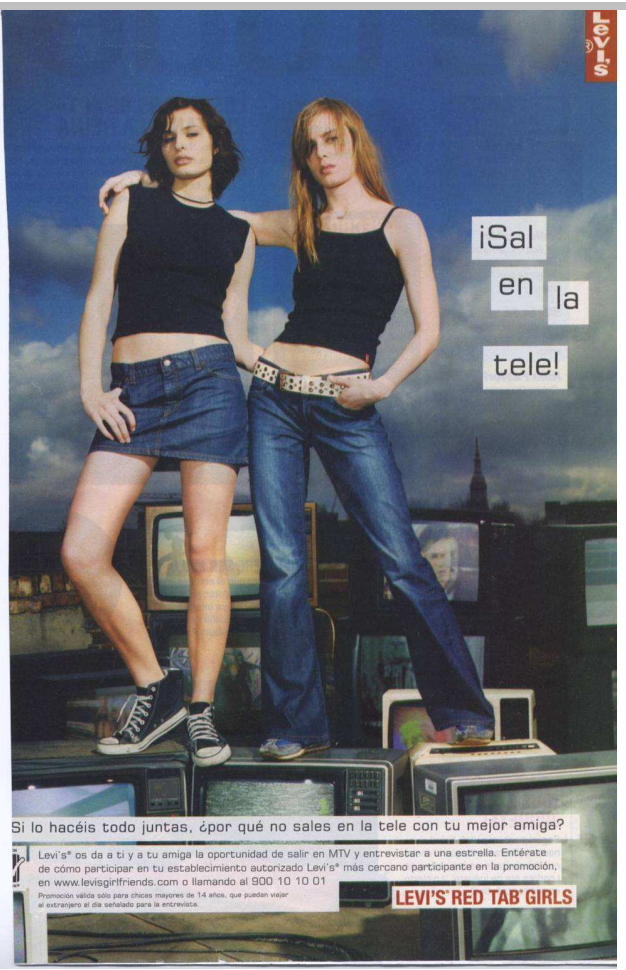

14

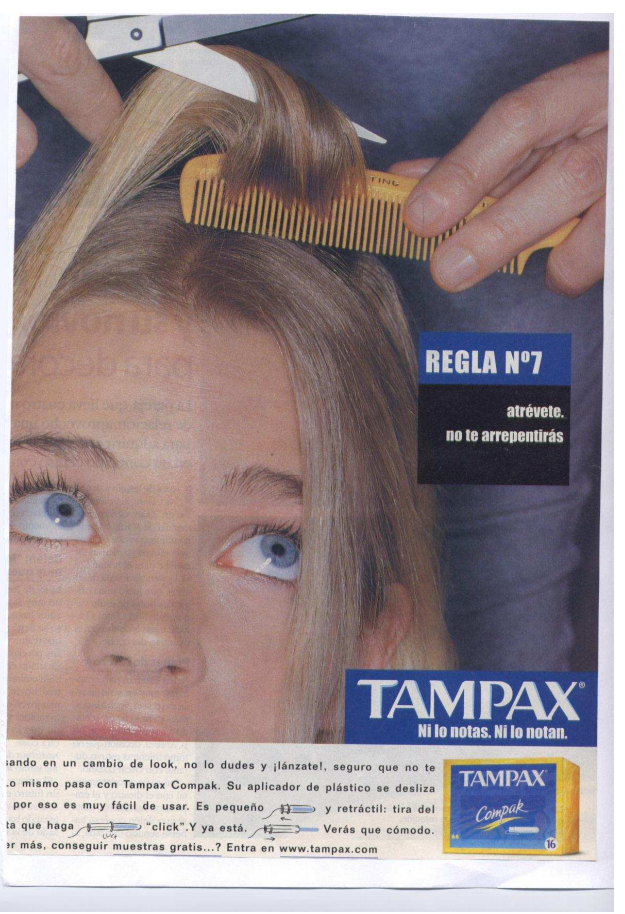

16 


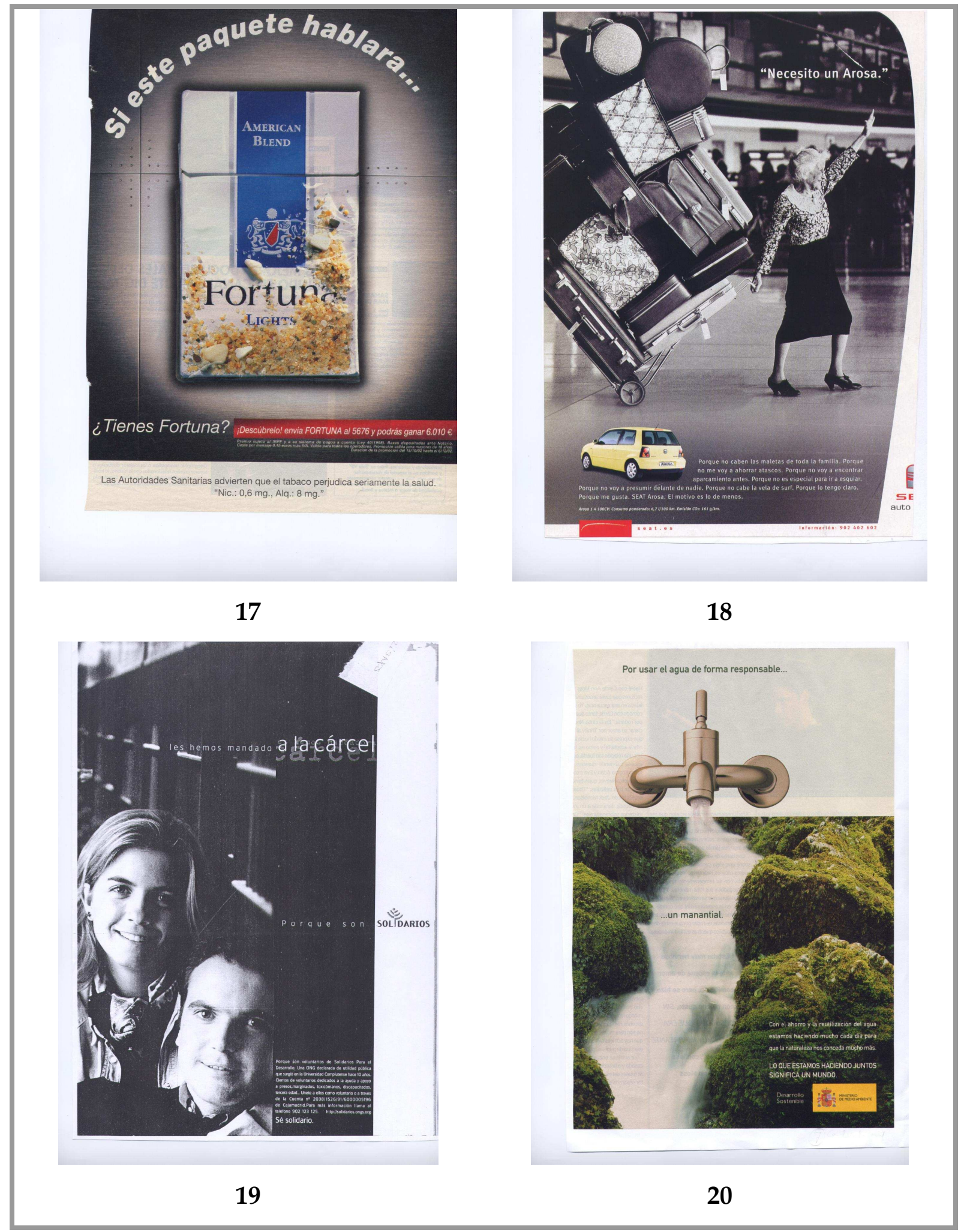

